\title{
The Legal Analysis of Rollover Data Services
}

\author{
Wenting Liu \\ School of Arts and Law \\ Wuhan University of Technology \\ Wuhan, China
}

\begin{abstract}
Cellphone data is popularized in our daily life, thus bringing new legal problems. Firstly, this paper presents a general overview of the content of cellphone data plan at home and abroad. Secondly, it gives a proper definition of mobile phone data and further analyzes the legal character of cellphone data plan. Thirdly, it points out that the operation mode that users are not allowed to carry forward unused monthly data will do harm to consumers' rights and interests. This paper ends with a suggestion that unused data at the end of the month will no longer just disappear and users are entitled to use it without time constraints which lays the basis for our operators to adopt a more reasonable cellphone data plan to fully protect consumers' interests.
\end{abstract}

Keywords-cellphone data; legal analysis; consumers' interests; operation mode

\section{INTRODUCTION}

In recent years, with the rapid development of mobile communication business, data traffic business occupies more and more important positions, which is one of the major business sources of telecom operators. With the high development of telecom, people place greater demands on the connectivity, thus dreaming to be able to access the Internet wherever they are, on their smartphone or other mobile device. At the early stage, surf the Internet with mobile device is so expensive that most people can't afford it, in order to promote and develop data service, telecom operators begin to recommend many kinds of suite business of data, the so called "data plan". A data plan is part of the service that mobile operators offer to give you connectivity anywhere under the sky. It is called a data plan because, in contrast to the traditional GSM service which offers voice and simple text transmission only, it offers data transmission through an IP network and ultimately a connection to the Internet, where multimedia resources can be accessed. A data plan involves getting you connected to a $3 \mathrm{G}, 4 \mathrm{G}$ or LTE network. Especially since 3rd-generation, which telecom operators focus mostly on has been switched from the calls, SMS business to flow, the mutable data plan prompted continually changes of the telecom operators. However, from the "monthly reset" mode to the "rollover data services", the great change reflects the consumers' demand of the data has greatly changed, the operators should not only focus on the development of themselves, on the other hand it can obviously prove the serious defects and deficiencies of the "monthly reset" mode. Consumers' aware of rights has increased significantly; they have started to use legal means to safeguard their own rights and interests.

\section{A. Mobile Data Plan of Other Countries}

Through investigation, mobile data plan of other countries will not be reset at the end of month, for example, Orange which is the biggest telecom operator in France launches a package where the unused data can be used without time limit; Russia's 4g network is so developed that the price of it is very cheap, and the first $4 \mathrm{~g}$ network operators Yota has launched a phone card, with which each month we can enjoy $4 \mathrm{~g}$ flow completely without limit, even in the subway, it can also be used unimpeded, monthly fee is only 240 rubles, about 25 yuan, the download speed of it is very fast. What's more, there is no charge of the caller id display as well as roaming or any other miscellaneous collection. While, if you pay 5 yuan, you can enjoy unlimited texting plan within whole Russia, and the call within the same operator is also free of charge.

TABLE I. The TyPicAl DATA Plan of Other COUNTRIES

\begin{tabular}{|c|c|c|c|c|c|}
\hline Country & ISP & Plan name & Speed & Data limit & Price \\
\hline Austria & Orange & $\begin{array}{l}\text { Mobiles } \\
\text { Internet } \\
3 \mathrm{~GB}\end{array}$ & $3 \mathrm{G}+$ & $3 \mathrm{~GB}$ & $10 €$ \\
\hline France & Orange & Internet & $3 \mathrm{G}+$ & FUP & $6.0 €$ \\
\hline Germany & $\begin{array}{l}\text { T- } \\
\text { mobile }\end{array}$ & $\begin{array}{l}\text { WebN'Wal } \\
\text { k connect L }\end{array}$ & $3 \mathrm{G}+$ & $\begin{array}{l}\text { 5GB } \\
\text { /Unlimited }\end{array}$ & $\begin{array}{l}39.95 \\
€\end{array}$ \\
\hline $\begin{array}{l}\text { Hong } \\
\text { Kong }\end{array}$ & 1010 & $\begin{array}{l}\$ 257 \\
\text { Handset } \\
\text { Connection } \\
\text { Plan }\end{array}$ & $\begin{array}{l}3 \mathrm{G} \\
\mathrm{HSDP} \\
\mathrm{A}\end{array}$ & $1 \mathrm{~GB}$ & $\begin{array}{l}\$ 259 . \\
0 \\
\text { HKD }\end{array}$ \\
\hline $\begin{array}{l}\text { United } \\
\text { Kingdom }\end{array}$ & Three & $\begin{array}{l}\text { Internet } \\
\text { Max } \\
\text { Add-on }\end{array}$ & $\begin{array}{l}\text { Up to } \\
7.2 \mathrm{Mb} \\
\mathrm{ps}\end{array}$ & $\begin{array}{l}\text { 1GB } \\
\text { /Fair use }\end{array}$ & $£ 5.0$ \\
\hline $\begin{array}{l}\text { United } \\
\text { States }\end{array}$ & AT\&T & $\begin{array}{l}\text { Data } \\
\text { Unlimited }\end{array}$ & $\begin{array}{l}\text { GPRS/ } \\
\text { E- } \\
\text { DGE/3 } \\
\text { G/HSD } \\
\text { PA }\end{array}$ & $\begin{array}{l}\text { 5GB } \\
\text { /Unlimited }\end{array}$ & $\$ 60.0$ \\
\hline Slovenia & $\begin{array}{l}\text { Si.Mob } \\
\text {-il }\end{array}$ & $\begin{array}{l}\text { Internet } \\
\text { Unlimited }\end{array}$ & $3.5 \mathrm{G}$ & $\begin{array}{l}\text { 20GB } \\
\text { /Fair use }\end{array}$ & $\begin{array}{l}19.0 \\
\in\end{array}$ \\
\hline $\begin{array}{l}\text { Netherlan } \\
\text {-ds }\end{array}$ & $\begin{array}{l}\text { XS4All } \\
(\mathrm{KPN})\end{array}$ & Go & $\begin{array}{l}768 / 38 \\
4 \\
\end{array}$ & $1 \mathrm{~GB}$ & $\begin{array}{l}20.0 \\
€\end{array}$ \\
\hline Finland & Cubio & 1MDpack & $1 \mathrm{Mb} / \mathrm{s}$ & FUP & $\begin{array}{l}19.9 \\
€\end{array}$ \\
\hline
\end{tabular}

Meanwhile, the telecom operators in some developing countries such as South Korea also launched a package; SKT is one of the biggest operators in South Korea which launch a package that the unused data can be used in next month 
until being used up. In Vietnam, the download speed of $3 \mathrm{~g}$ network is faster than Wifi, which means that the $3 \mathrm{~g}$ networks in Vietnam is much more developed than many developing countries and even in the front of the developed countries. For example, Viettel have launched two different packages: first one is Dmax200, designed for those who have great demand of the Internet, 3 GB per month; it only costs about 60 yuan. While to those have less demand of Internet, they can just use MiMax packages, $600 \mathrm{MB}$ per month, it only costs about 21 yuan. And after using up all the data in the plan, they will not be charged for any fee when they continue to surf the Internet.

\section{B. The Mobile Data Plan in China}

As we all know, China has three biggest telecom operators, compared with other two operators, China Mobile has more base station and can provide stable signal even in the remote mountainous areas or on the sea, but it will cost more when we demand for the same amount of the data. While the data plan of China Unicom is more affordable, but sometime it is not as stable as China Mobile, each has its own merits. In recent years, China Telecommunications tend to pay more attention at wired broadband, thus lacking competition in mobile data plan.

To sum up, taking the mobile data plan of other countries into consideration, and with the increasing demand of the data, this paper has put forward a series of questions, the most important one is "whether the unused data should be reset at the end of the month ".

\section{Mobile Data ANALYSIS OF THE LAW}

Three operators to data flow based pricing model, called mobile traffic packages. There are three types of monthly system, based on the use of business pricing and package pricing. At this stage the main model is the package pricing, which refers to the user to pay a monthly fees, so they can enjoy a certain amount of business, more than part of the additional charges It combines the advantages of the former two, allowing users to understand the size of the data service usage, we should subdivide the market and users, to a certain extent we also meet the different needs of different users, than we can make the development of appropriate fees basis properly. In addition, more operators will flow, content business and voice service together to form all-round package, not only can satisfy the user's choice, but also bring more competition for the market, they can attract users' attentions, improve their business strength. [1]

\section{A. Mobile Phone Flow Package Belongs to a Telecom Service Contract}

Defining the concept of telecommunication is the basis of studying the connotation of telecommunication contract. China's "People's Republic of China Telecommunications Regulations" article second of telecommunications were clearly defined, "said Telecom as mentioned in this Regulation refers to the use of wired or wireless electromagnetic systems or photoelectric systems, transmission, transmit or receive voice, text, data, images, or any other form of information activities." Telecom will be transformed into a variety of telecommunications services for the public, and telecom operators to provide this kind of telecommunications services, to charge a certain fee, which is the telecommunications business. Because of the particularity of the products and services provided by telecommunications services, it is different from the traditional service industry: First, the products provided by them are intangible. Second, the particularity of telecom service delivery media. Third, the public is not only the carrier of telecommunications services, but also the implementation of telecommunications services.[2]Therefore the nature of mobile phone traffic with Telecom's connotation, in addition to telecom operators and mobile phone is not clear flow of manufacturers and producers, whose main function is to build more base stations and communication equipment using the platform to build a bridge, to enable consumers to obtain the flow in the channel, which charge platform facilities cost, service is in essence operators in the contract, the consumer is provided by the operator's service to enjoy the convenience of traffic. In the "notice" on issues related to standardization of telecom service agreement will first telecommunication service contract clearly defined as: "telecom operators in order to reuse prepared in advance, between the standard and the telecom user's rights and obligations of the contract." Based on this, we can define the concept of the telecommunication service contract as a contract which is provided by the telecom operator, which is set up, changed and terminated by the telecommunication operator, and the contract is repeated. Therefore, mobile phone traffic packages are included in the scope of the telecommunications services more appropriate. After defining the connotation of the telecommunication service contract, the nature of the telecommunication service contract will be defined. The author's view is: telecommunication service contract belongs to nameless contract law, the contract content and fifteen kinds of contract are not the same, but in the current law of our country telecommunication service contract has no clear legal regulations, the name and the content of the contracts were not expressly. The service contract also belongs to the category of nameless contract, so the legal application of the telecommunication service contract should be carried out according to the law application of the nameless contract. The application of mobile phone packages should also be applicable to the law of the corresponding unnamed contract law.

\section{B. The Mobile Phone Package of the Legal Relationship between the Three Elements}

We should clear mobile phone package contract is a telecommunications service contract, so it is necessary to further explore the legal relationship between the three elements.

1) Mobile Phone Package Main Body: From the above mobile phone package contract, you can clear the legal relationship between the main body, including consumers and operators. Operators in China mainly refer to China Mobile, China Unicom and China Telecom, they are called 
the big three, and they are service providers, the consumer need to pay a reasonable price to get traffic.

2) Mobile traffic package object: Explore the flow of mobile phone package contract object, we can clearly find the behavior of the two parties is different. As operators, its behavior is to provide consumers with traffic packages service, as consumers, their behavior is to pay the appropriate price to the operator. In addition, it is necessary to define the subject matter, the definition of traffic, after discussing the content of the object: The mobile network communication is actually the communication between users, but because of the limitation of the communication distance, it is necessary to use the platform built by the telecom operators to realize the long distance stable communication. ${ }^{[3}$ For operating costs, profit considerations, telecom operators will charge a fee in the mobile phone platform, the flow field, we call traffic charges, charging in bytes (Byte), which contains the signal between the user and the upload, download platform produced by all the bytes. According to the above definition of flow, we know that the flow has a certain particularity.

First of all, the flow is different from the traditional tangible property law. The object of the real right law refers to the human body, which can be controlled by human beings, has the independence and can satisfy the human body and the natural force. However, the flow does not conform to the definition of the property law. Traffic is a measure of the amount of use of a communication channel provided by the operator to the consumer. ${ }^{[4}$ Consumers are not in the consumption flow itself, but in the use of communication channels. On the other hand, traffic is not independent. Consumers can use the package flow is based on the smooth flow of mobile operators communication channels and consumers with the operator's mobile network connected premise. Therefore, traffic cannot exist independently from the communication network.

Second, the flow is different from intangible property. [4]In law, we divide intangible property into nothing and intelligence. On the one hand, it is different from the intangible property, electric power, gas and heat, which belong to a special commodity, and it is also a matter of law. Because the subject matter is objective and can be used by people, it is classified as a kind of "thing" in civil law, which belongs to intangible property. In real life, they are the independent use of each household, proprietary, and cannot be shared, but also cannot be transferred, but the flow can be transferred, can share the particularity. On the other hand, it is a kind of intangible property right, which is different from the intangible property and intellectual property. However, the property of traffic is not a factor of intellectual achievements, it cannot be attributed to the category of intellectual property rights, on the contrary, it belongs to the category of nameless contract.

3) The content of the mobile data plan: After defining the main body and the object of the mobile traffic package, it is necessary to explore the content of the mobile phone package contract, to determine the rights and obligations of both parties. Urges both sides to enjoy the rights, but must fulfill the corresponding duty. Firstly, in dealing with the various mobile phone businesses, the parties should be through reasonable, equal, agreed to express the meaning of the final contract.[5]Therefore, for consumers, the mobile phone tariff packages enjoy the right to know, and have the right to require the operator to set the contents of mobile phone packages, tariff consumption specific explanation. Secondly, consumers enjoy the possession and use of traffic. Through the analysis of the legal nature of the flow, consumers cannot obtain the ownership of the flow, and through the operation of an agreement to pay the price, in accordance with the provisions of the law can be used in a reasonable manner. Finally, consumers enjoy the right to dispose of the flow, consumers and operators to achieve the flow of packages after they reach agreement, they are able to own the flow of punishment, allowing consumers to share, exchange and exchange of traffic. At the same time, the buyer can enjoy the rights of consumers to bear the obligation, and they must pay a reasonable fee, in order to occupy the flow.

As operators, they are able to have a right to obtain the cost of payment from consumers, through the collection of fees to provide consumers with the corresponding traffic and the corresponding services. On the one hand, the operator needs to be in a timely manner to the mobile phone users beyond the prescribed use of traffic alerts, and when the mobile phone users in the use of mobile phones across the country or across the region, the timely implementation of the obligation to remind. On the other hand, the operators should invest more resources to build base stations, to ensure that the user's mobile communications can play a stable, and they should provide practical security for consumers to use the flow. In contrast, the responsibility of operators' obligation is more significant.

\section{RESETTING THE UNUSED DATA ViOlATE THE INTERESTS OF CONSUMERS}

From the analysis of the law, we can find that the contract about mobile data plan signed by consumers and operators is a new unnamed service contract. In the past, at the end of each month, the operators will reset the unused data, and it is clearly declared in the contract, which greatly violates the interests of consumers. Obviously, when consumers pay for the mobile data plan, their rights and interests should be taken seriously, and they have the right to demand for the equal services. Unfortunately, the previous mode of the data plan completely deprives their right to use up the data they have paid for. Even in the newly launched mode where the unused data can be used firstly in the next month, that is to say, now the data in the mobile data plan can be used in two month, it seems to relief the contradiction between consumers and operators to a certain degree, but people are still not satisfied. In their opinion, in this mode, they can still not make full use of the data in the data plan, more or less, some data would be reset. That's to say, the telecom operators are violating the rights and interests of consumers as usual. All in all, whatever kind of data plan the 
operators adopt, so long as the unused data would be reset, it's unreasonable and it's inequality imparity clause.

\section{CONCLUSION}

Now, typical packages for data plans in China are (as a matter of example) $100 \mathrm{MB}, 200 \mathrm{M}, 500 \mathrm{M}, 1 \mathrm{G}, 2 \mathrm{G}$ and unlimited. The further the limit, the more your monthly charge is, but the more you move above, the lesser your cost per MB is. So as to avoid paying expensively for overdue data on the one hand and wasting unused data on the other, it is important to estimate your data usage per month before Chinese telecom operators launch a reasonable mode where the unused data will not be reset. To help people with this, there are numerous data usage calculators online.

In conclusion, I think the mobile data changing from "reset every month" to "reset every two month" will not balancing the interests of both sides fundamentally, let alone ensure the long-term interests of consumers. Mobile data is a service that consumers have equally paid for, so they should have the right to continue use those unused data without any restrictions, no matter how long it will take.

When talking about the management of mobile data, this paper advise telecom operators should continue to adjust and optimize the mode. Whenever operators consider their own interests, at the same time they should pay more attention to avoid infringing on the rights and interests of consumers. That's to say, compared with interests, they should focus on fairness. What's more, all the telecom operators in our country should learn the data mode of others and must be able to do reasonable use of it. They should not take resetting unused data a way to make profit. And they must provide various kinds of choices for different people in order to meet different needs, so consumers can easily change their data plan as demand changing, what fundamentally protects consumers' rights, finally get a win-win situation. This paper firmly hope that with the development of society, we can have a much more reasonable solution, support and maintain consumers' interests to the greatest extent, thus promoting the healthy development of mobile data.

\section{REFERENCES}

[1] Wang Zejian. Real Right of Civil Law [M]. Press of Cambridge university, 2012, (In Chinese).

[2] Liang Huixing, Chen Huabin, The property law [M]. Press of Law.2010; (In Chinese).

[3] Wei Zhenying, Civil Law [M]. press of Cambridge university, press of Higher education ,2000:118 (In Chinese).

[4] Ji Jing, Internet law construction in the form of new property interest, in the perspective of flow right verification rules put forward [J]. Journal of northwest university of political science and law (law science), 2016(3):182.

[5] Sun Zhongmei,,Research on telecom service contract [D]. China University of Political Science and Law. 2003:51. 